\title{
- Distar
}

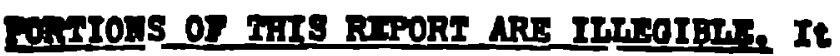
has beon reproduood f rom tho bost avallable oopy to pornit tho broadost possible avaljab11ttr.

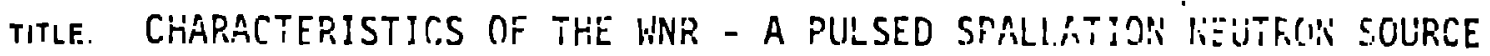

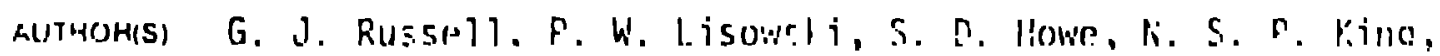
a . M. Meier

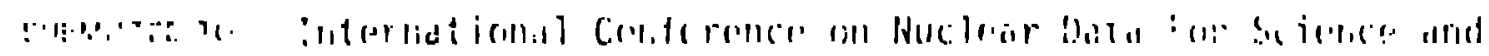

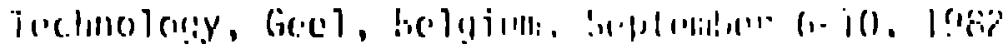


The Weapons Neutron Resaarch factilisy (WNR) is a pulsed spallation neutron source in operation at the Los Alamos National Laboratory. The WNR uses part of the $800-$ MeV proton beam from the Clinton P. Anderson Meson Physics Facility accelerator. By choosing different target and moderator configurations and varying the proton pulse structure, the WNR can provide a white neutron source spanning the energy range from a few meV to $800 \mathrm{MeV}$. The neutron spectrum from a bare target has been measured and is compared with predictions using an Intranuclear Cascade model coupled to a Monte Carlo transport code. Calculations and mecasurements of the neutronics of WNR target-moderator assemblies are presented.

[800-MeV protons, spallation, neutron spectra, I meV-800 leV neutrons, Intranuclear cascade Predictions]

\section{Introdurtion}

The Weapons Neutron Research factllty'i, is an oierational pulsed spallation neutron soume at tho Los Alamos Nat; onal Laboratory. At the WNR. porition of the intense 800 -MeV proton besm produceo by the Cinton $P$. Anderson Meson Physics Fecllliy (LAMPF)' bombards a target to produce an intense mite-neutron source. Variable proton pulse withs are avollable at the Whe giving time-of-fight (TOF) expertmental capabllity for neutrons frim a few meV to $800 \mathrm{MeV}$. The flexibllity and capasillty of the WMR w/11 be enhonced by the addition of "Proton Storage Ming (PSR)". The PSR, presently under construction and scheduied Por operation 1, 1986, wll be abla to alter the Intensity, time structure, and repetition rate of the WWR proton puise. He present here descriptinn of the WWR, its aperating characterlstics. and some neutron spe:tra measurements and calculatlons.

\section{Focil1ty Descriotion}

The WWR is one of several experimental facllities located at LAMLF; the layiut of the WNR is Pllustiaced in Fig. i. At prisent, the hlgh-current - ree (target 1) is capable of accep:ing up to 20 IIA of froton becm. Target I has vertical target. is surrounded by i-m dian by $2-m$ high cvilndrical vold. and is shieleied by 3.7 -m-xhick I $m$ inoted 1ron-concrete structure. Target I has very flexthle terget-moderator - reflector handing scheme: all three conflosirations hown in Fig. are employed. The ortentetion of the refiected 'T'-shape moderator in target 1 is lllustrated in Fig. 3. For use witi. the PSR, the shielding and hanilling schme lor iargets, moderators, anc reflectors is beins upgreded for operation with 100 "A of proton current. Heutron beems arn extrected at $90^{\circ}$ to the taruet axto flight paths fras 5 to several hundred meters are avellable. Bastc research in iuclear physics and materials eclence reseanch is done in the high-current target area.

The low-current torget arer (target 2) cen accept up to 0.1 wh of proton tem or usen fer mensulements wth neutrons from tarast 1 . The herlcontel proton bear in terget? strikes corget. mich in be viend at. varlety of engles fliom $7.5^{\circ}$ to $\left.165^{\circ}\right)$ to the protun ber. We heve imple. mented $30-m$ flloht paths at $7.5^{\circ}, 16^{\circ}$, and $31^{\circ}$ to study (p,xni- ond (p,xp)-tyne reactions. and are cc sidering longer flight paths and other angles. In toriat 7. Whave lso devaloped the capablilty to measure for Bon-mev-proton sollintion reac(lons). 1) spatis! distitutions of (ahsoluty) "thermal" neutror surfare lluxes from moderators 2) absclute meutroi epectra for energies ( 10 ev. and 3) neutron pulse thapes for energice 0.172 eV. Me cse thls unfque experimental catablifty (combineci wth excellent comutationel support) to ptimize the neutrontes of the high-current production target system in terms of neutron beam fluxes and puise wdtlis, and minimizing highenergy neut-on bem initamination and assoctated backgrounds $1, \mathrm{~s}$, ?.

Using targets placed ir the WMR beam chanriel, we have constructed 200-1n filght path at $0^{\circ}$ to the protun beam. Thls fllght path combined with unique WNR proton pulse structure allows high resolution experimerits to be performed at reutror. energles up to $800 \mathrm{MeV}$ ".

\section{Operating :haracteristics}

With or without the PSR proton bean, the WNR can operate in two modes. These mides arc as follows:

- w thout PSR

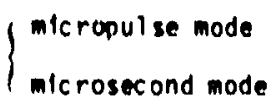

- w1th PSR

short bunch hig frequency mode

long bunch high

A summary of the WNR priton pulse characteristics is given in Toble 1. At present. the wldth of the WW proton pulse cin be varled from 200 ps to $B$ 4s. The PSR Wll paovide additional pulse-wdth and rapetition-rate combinations with higher instantanous intensities, and more average protor currents.

\section{Neutronfc Cliarecteristics}

Tho varlous deslats of target, target-noderator. and teroet moderator - roflector conflouratlons for terget 1 isee $\mathrm{F} / \mathrm{g}$. 2) a strongly fnfluenced by the need for neutrons $w$ th energles langlng from. fow mev to aOO MeV having pul se widths a nerrow as prectical. We use a bare terget to produce neutrons with energles $z$ l00 ket! en unreflected "fast' moderator for ieutrons with energles? ev $\leq f \leq 100 \mathrm{keV}$, and a reflerted system for nautrons wth energies $s$ i ev.

The high-resolution bere target presently used in terget 1 conslsts of a Ta cyllnder 12.5-cm diam by 15-cm longl placed in watur cooled Al canteter. We mensurad the incutron spectrum let $90^{\circ}$ to the protion bean) Irom such a terget: the results ore shown in Fio. and $c$ mored with calculated pre. dictions. The barectarget data were mesured

- The minimum proton pulse with at the WWR wa meesured to be approximately 200 ps Fum. Thls corresponds to elnvle lampr icroputse. 
at 39.4-m flight path using Tof techntques and scintillator of know efficlency. For these measurenents, we used 200-ps-wide proton pulses spaced 11 is apart at $12 \mathrm{~Hz}$. Charged particle contamination of the neutron bearn was observed to contritute signiflcantly to the detector count rate at energies $>100 \mathrm{MeV}$ and was eliminated using sweep magnets. The experimental data have been nomalized to calculated results at $10 \mathrm{MeV}$

In target 2, measured the neutron beam flux from reflected 'T'-shape muderator using a $B F$ detector, 5.6-m flight path, and $: 5 \mathrm{~ns}$ proton pulses at $120: 1 z^{7}$. The measured data are shown in Fig. 5 for $100 \mathrm{~cm}^{2}$ fleld-of-view at the moderator surface. The target was 4.5-cm-dien by 25-cm-long $W$ rod. The $\mathrm{CH}_{2}$ moderator had $0.0025-\mathrm{cm}-\mathrm{th} f \mathrm{ck}$ Gd poison sheet located $1.91 \mathrm{~cm}$ from the "wed surface. The moderator was isciated from the Be refiector by $0.076 \mathrm{~cm}$ of $\mathrm{Cd}$. Tie Be reflector was a cube with a 46-im side. Keasured neutron pulses iran the Cd-decoupled, Gd-polsoned $\mathrm{CH}_{2}$ moderator are fllustreted in F19. 6 .

State-of-the-art Monte Carlo codes are operational on the Los Alamos computing system. These codes Inclues the ORN High Enery Miclean Meson Transport Code (FETC) ${ }^{\circ}$, and the sophisttcated Los Alamos coufled neutron-photon triansuort code MCNP'" We usid these codes in the calculation shown in Fig. 4. He have also computed the neutronics of moderated systems. In particular, we have calculated the outward neutran current at - moderator surface fur the two configurations shown in Fig. 7: the results re given in Fig. 8 He used $2.5-\mathrm{cm}-d 1$ am by $15-\mathrm{cm}-1$ ong Ta target in the unreflected slab-moderatior computations. A 5-cm-dian by 25-cm-1 ong Target was used in the reflected Hng-moderutor calculetions. The reflector was Be cube (50 am on slde). and the moderator was $3.5 \mathrm{~cm}$ fram target center. The Cd-decoupler was $0.076-\mathrm{cm}$ thlck, and the Gd poison sheet $m: 0.0025-\mathrm{cm}$ thick placed $1.5 \mathrm{~cm}$ from the vlewed surface. Mote in Flo. \& the decrease in thermal mutron current when a roflected system is decoupled and polsoned; the thermal neutron pulse characteristics are, however. slanlficantly better for the decoupled/polsoned system. In Fiy. 8 . the mutron current from the unrefiected slab-moderator is averaged over $400 \mathrm{~cm}$, mereas the neutron current fram the wing-moderators were averaged over $100 \mathrm{~cm}$ '. The presence of nigh-energy neutron component, beginning ot $~-1$ MeV, in coiter-looking fleld-nf-view from slab morlelutor lcompared to the offut field-of-view in wing geometryl can be sean in Fig. B. This high-energy neutron component can extens up to fow hundred Mav?

The charecterization of the WR mutrontc capehillty will cont!nue in an effort to intercompare calculatlors wth experiments on in obsolute basts.

\section{Aknowledgements}

Thls work was performed under the ousplcas of the U.S. Depertment of Energy. We cknowledge tme help of t.R. Whitake in prepering the plgures and R.E. Proel in our - umputing effort. Our thanks to Anselima Martinaz for typing the paper.

\section{Rarerences}

1. G. U. Russell, LA-6020, Los Almos Netlonal Laboletory (1977).

2. G. J. Rusrell, P. M. Llsownkl and N. S. P. ling. Int. Conf. on Meistron Phys. and Mucl. Data for Reactors and other Appl. Purposes. liariel1. England (1978).
3. M. S. Livingston, LA-6878-MS, UC-29 and UC-34, Los Alamos National Laboratory (1977).

4. G. P. Lawrence, et. al., XIth int1. Conf. on HIgh Energy Accel., Geneva, Swtzerland (1980).

5. G. J. Russell, J. S. G1lmore, R. E. Prael, H. Robinson and $S$. D. Howe, Symp. Heut. Cross Sec. from 10-50 MeV, Brookhaven Matl. Lab. (1980).

6. G. J. Russe1i, M. M. Meler, J. S. Gilmore, R E. Prael. H. Robinson and A. D. Taylor, KENS Report Ii, YEK, T sukuba, Japan (1980).

7. G. J. Russell, M. M. Meler, H. Robinson and A. D. Taylor, Juiltch-Conf-45, ISSN-0344-5789. KFA, ilitch, West Genr:any (1981).

8. P. W. Lisowsk', et. Al., Phys. Rev. Leiters, 49, 255 (1982).

9. G. J. Russe11. Trans. Am. Nuc 1. Soc., 27, 861 (1977).

10. T. H. Amstrong and K. C. Chandler, ORM-4744, Oak Ridge National Laboratory (1972).

11. Los Alamns Monte Carlo Group, LA-7396-M, Los Alamos Nacional Laboritory (198i). 


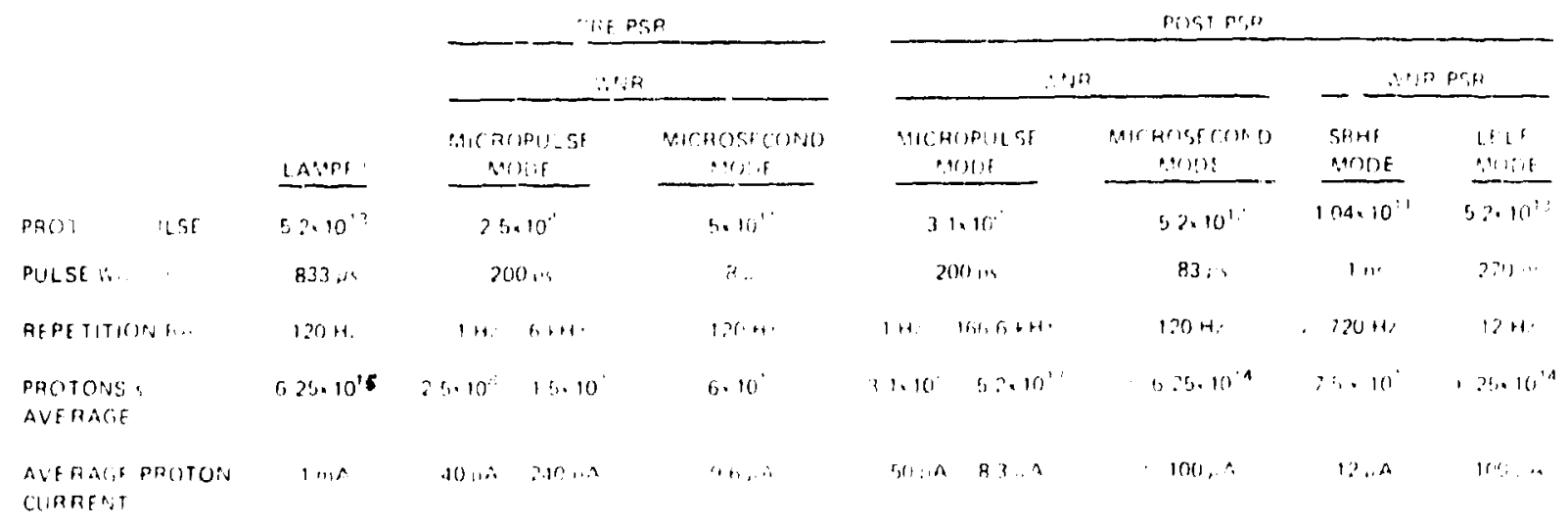

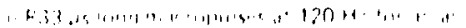

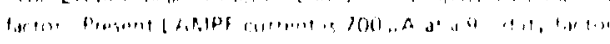

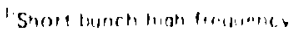

Lomu bunsh low Hennoner

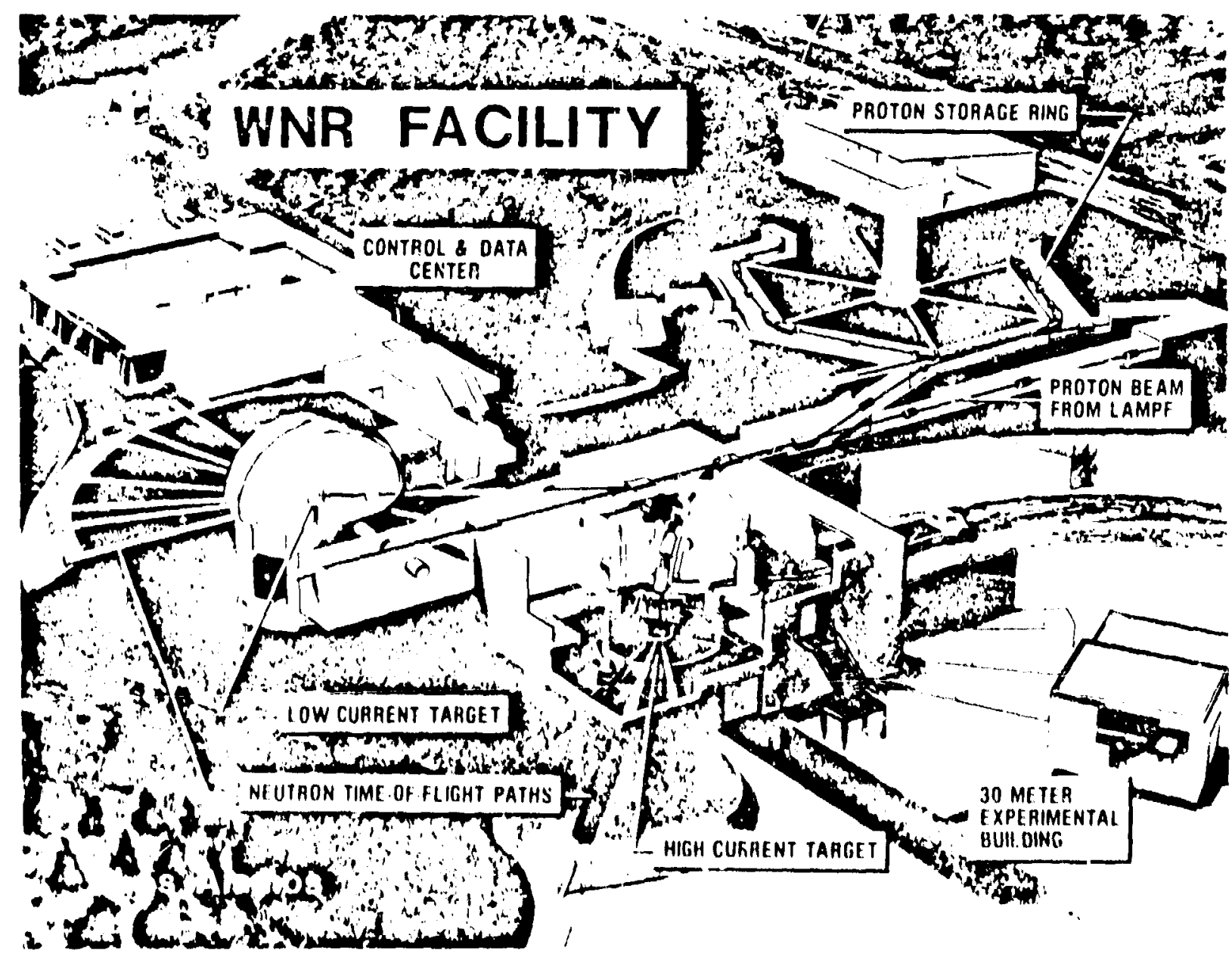

F1g. 1 This elqure shuws a layout of the WNR end the location of the proton storage ring. The high.cument target is located in proton storage ring. The high.cureent target is located in paths. The low-current taroet is locoted in a horizontal proton beam and viewed by 11 horigonts fllght paths and one vortical light path. The $0^{\circ}$ llight path extends out the end of the froton heam channel hetwern the high- and low-cureent target areas. 


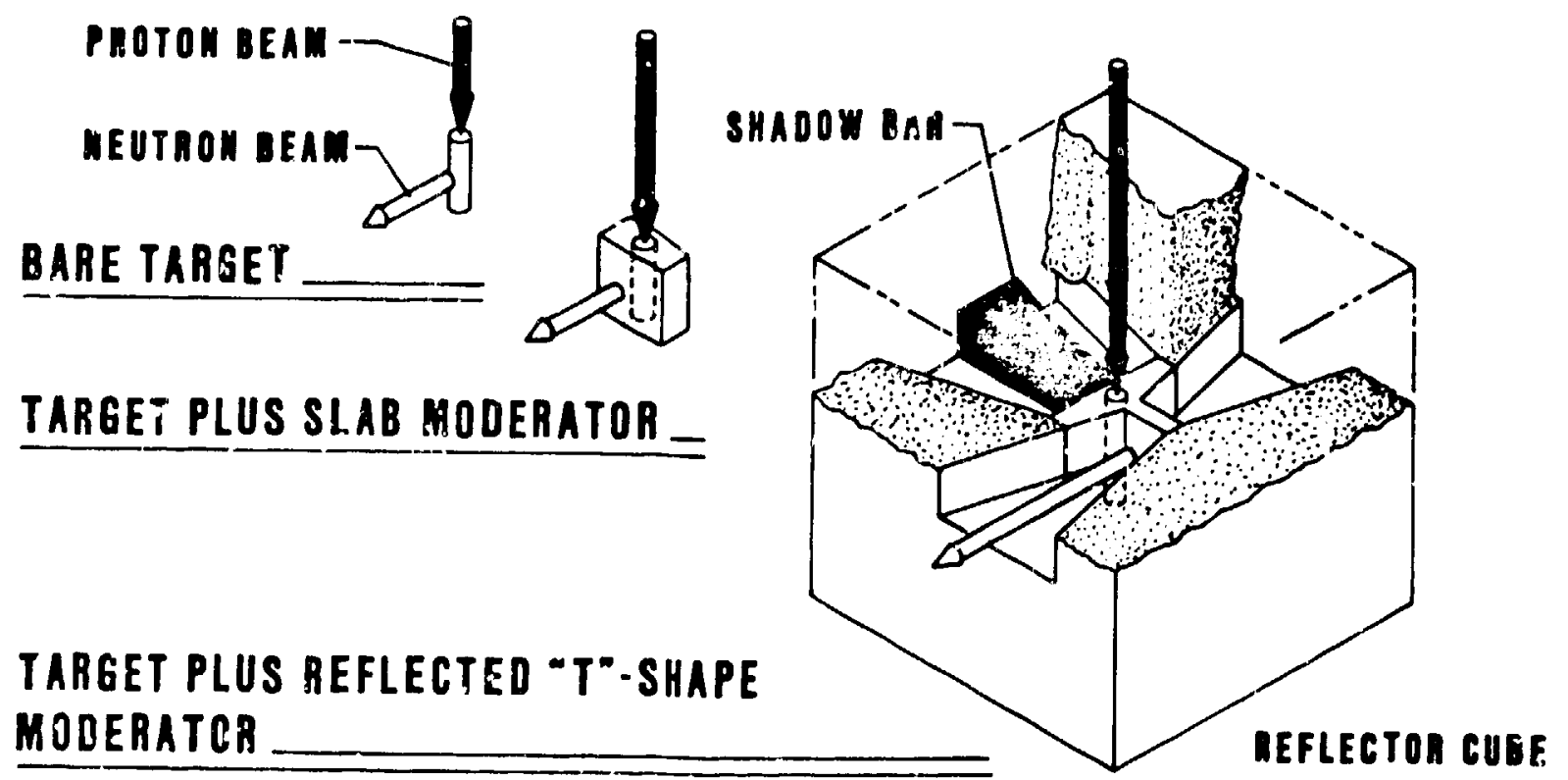

519. 2 Veutron prodiction configurations presently in use in the migh-current tarapt area.

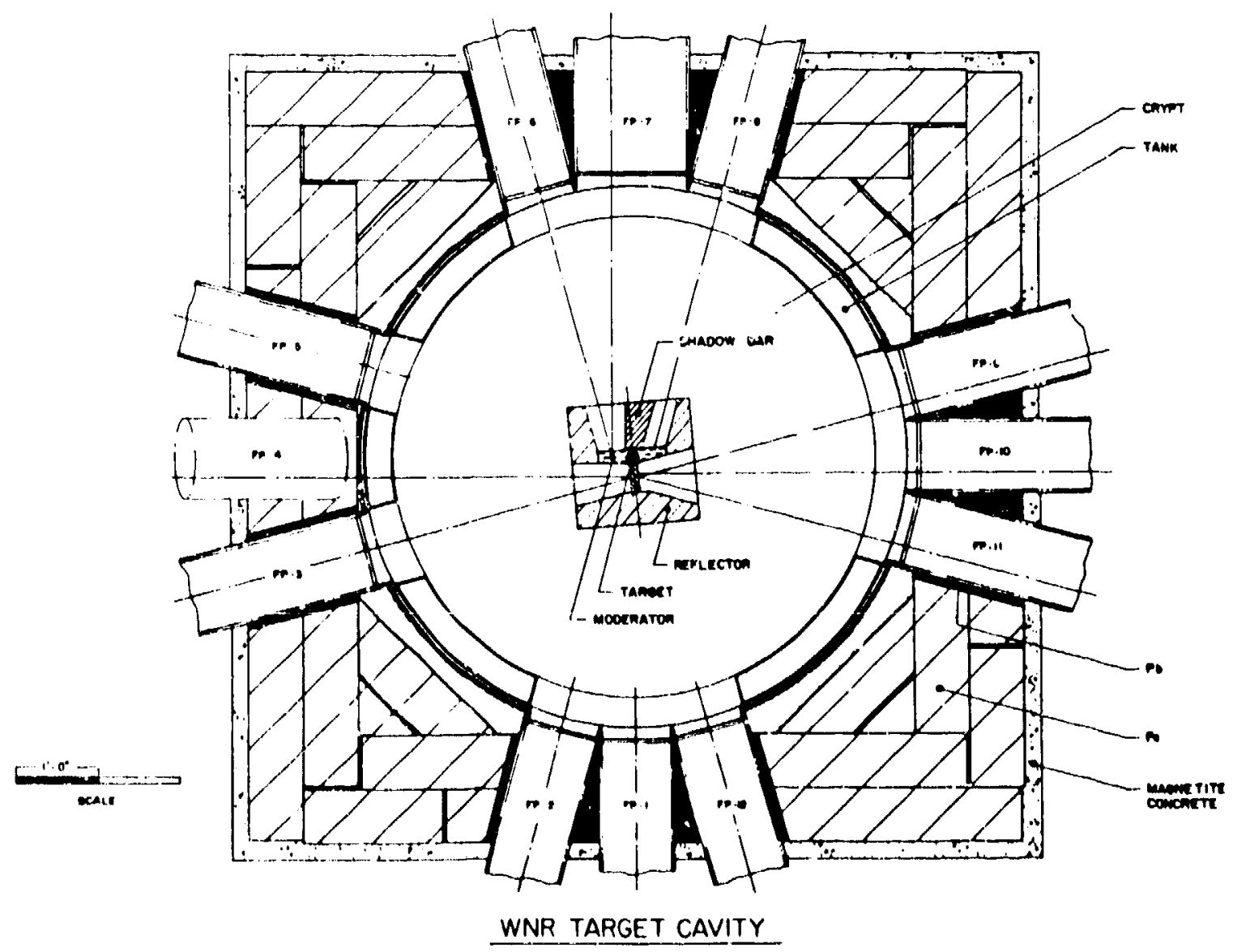

Fig. 3 Preselit orlentation of the reflected ' $T$ '-shape moderator in the high-current target area. 


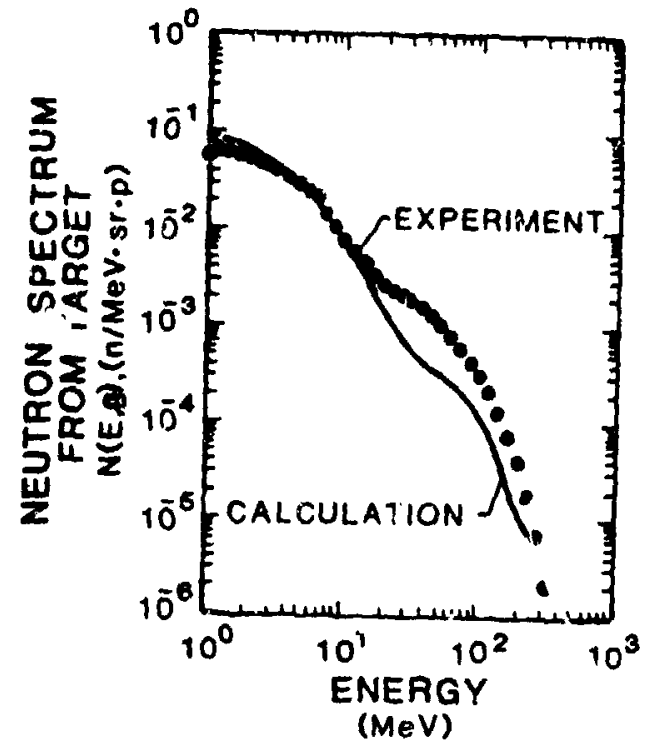

Fig. 4 Bare target spectrum (at $90^{\circ}$ to the proton beam axisl enitied from the cylindrical surface of the WNR Ta target. The field-of-view at the target surface encompassed the fult target of ameter but linited the height seen to $4.4 \mathrm{~cm}$ centered $3.8 \mathrm{~cm}$ fram the top of the target.

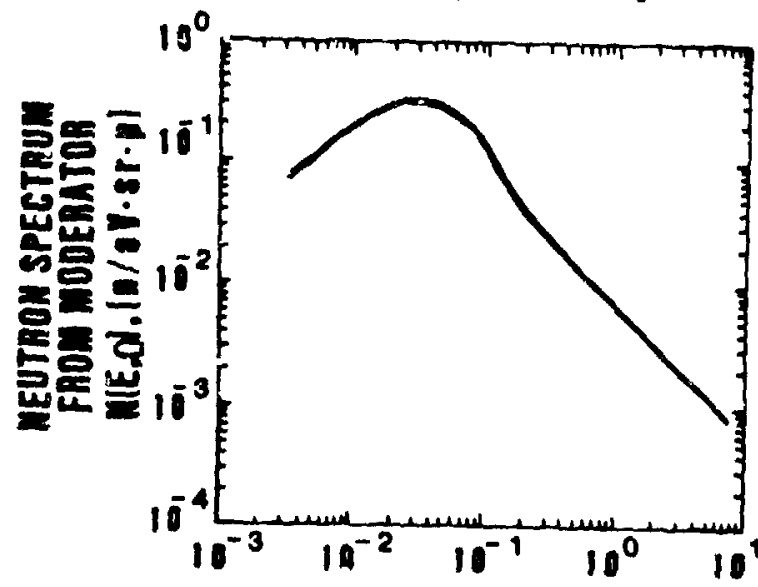

ENEBGY IUY

F1g. 5 Measured neutron spectrum enitted (at $50^{\circ}$ to the medirator surfacel from reflect-
ad wing-modirator.
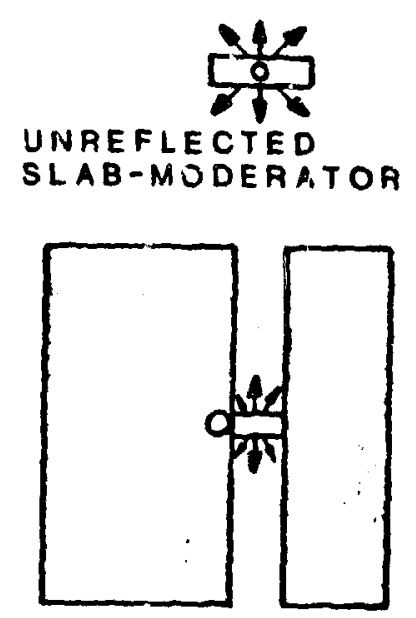

REFLECTED

WING-MODERATOR

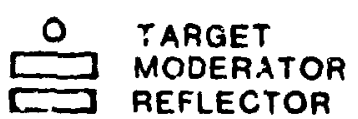

Fig. 7 Illustration of gecmetries used in calculating neution leakage currents.

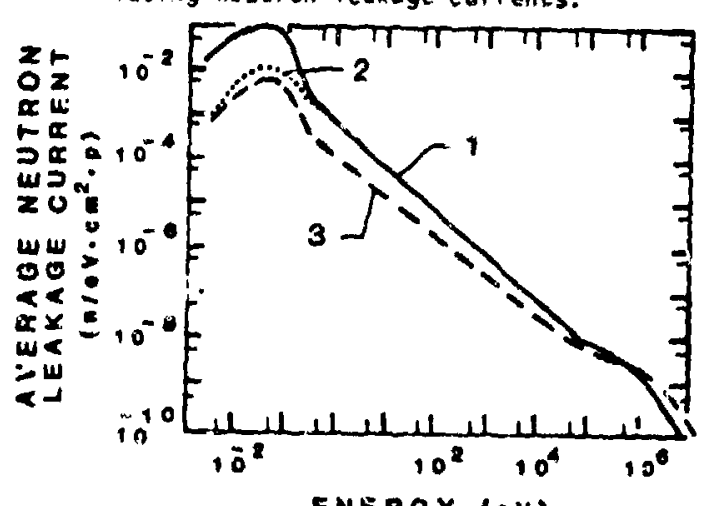

19. 8 Celculated reutron leakege currents averaged over the entire moderator surface for three conflgurations: 11 ecil pled refiectef wing-maderator $15 \mathrm{~cm}$ by 10 $\mathrm{cm}$ by $10 \mathrm{H}$ H 10 2) $\mathrm{Cd}$ Gd-poisoned reflected im by $10 \mathrm{~cm}$ by $10 \mathrm{~cm} \mathrm{HzOl,} \mathrm{and} 31$ unref $7 e c t e d$
by $\left.20 \mathrm{~cm} \mathrm{H} \mathrm{H}_{2} \mathrm{O}\right)$.

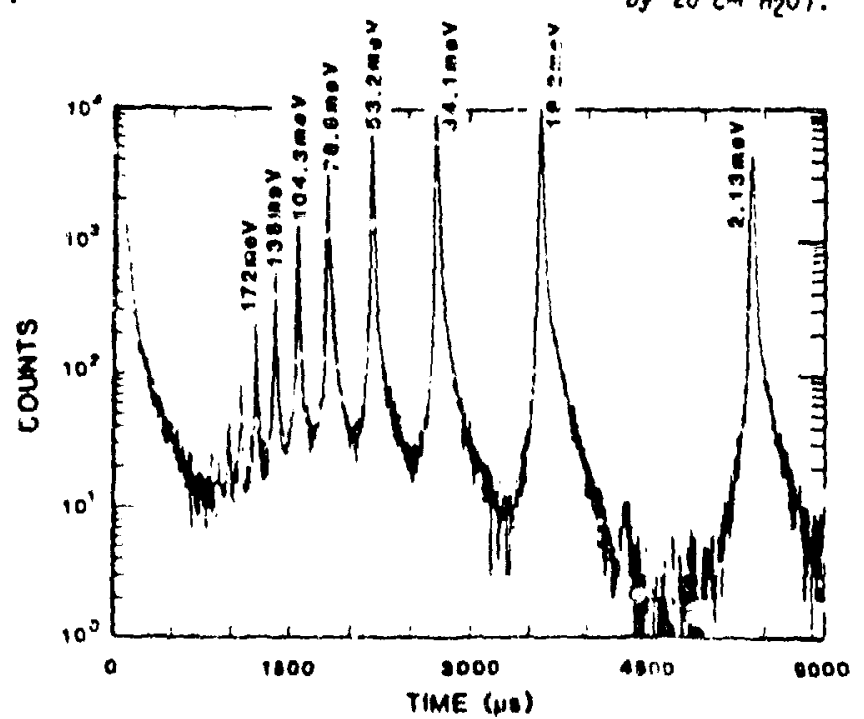

Fig. 6 Meisured neutron time distributions from a ca-deccutied Gd-pot soned reflected wing-moderator. 
The Weapons Neutron Research facility (WNR) is a pulsed spallation neutron source in operation at the LoS Alamos National Laboratory. The WNR uses part of the 800-MeV proton beam from the Clinton P. Anderson Meson Physics Facility accelerator. By choosing different target and moderator configurations and varying the proton pulse structure, the WNR can provide a white neutron source spanning the energy range from a faw meV to $800 \mathrm{MeV}$. The neutron spectrum rim bare target has been measured and is compared with predictions using an Intranuclear Cascade model coupled to a Monte Carlo transport cocie. Calculat uns and measurements of the neutronics of WNR target-moderator assemblies are presented.

[800-MeV protons, spallation, neutron sf ctra, I meV-800 MeV neutrons, Intranuclear Cascade Predictions]

\section{Introduction}

The Yeapons Neutron Research facllityli, is on operational pulsed suallation neutron source dt the Los Alamos Hational Laboratory. At the WHR, a portion of the intense $800-M e V$ proton beam prcfuced by the Crinton $p$. Anderson Mnson Physics Facility (LAMPF; ${ }^{3}$ bombards a target to iroduce an intense thite-neution source. variable proton pulse wdths are avaliable at the MNR giving time- of-flight (TOF) experimental capablifty for neutrons from few meV to $800 \mathrm{MeV}$. The flexibll1 ty and capability of the WHR will be enhanced by the oddition of aroton Sturage RIng (PSR)". The PSR, presently under construction and scheduled for operation in 1986, rtil be able to alter the Intensity, time structure, and repetition rate of the WNR proton pulse. He present here description of the WNR. its ocerating characteristics, and some neutron spectra measuraments and calcuiations.

\section{Faclity nescription}

The WNR is one of several experimental facllities located at LAMPF: the layout of the WNR is lliustrated in FIg. i. At present, the high-current area (target 1 ) is capable of accepting up to 20 uA of proton bean. Target 1 has vertical torget. 1s surrounded by $2-m$ dlam by $2 \mathrm{~mm} h 1 \mathrm{gh}$ cylindrical vold, and is shielded by 3.7 -m-thlck ieninated iron-concrete structure. Target 1 has very flexthle target-moderato: - reflector handling schene; 11 three conflguretions shown in F/g. ire employed. The ortentation of the refiected ' $T$ '-shape moderator in target 1 is 1llustrated in Fig. 3. For use with the rSR, the shielding and handling scheme for targets, moderators, and reflectors is being upgraded for operation witl 100 uA of proton current. Neutron beans are extracted ot $90^{\circ}$ to the target axis: llight paths from 5 to several hundred meters ere avallable. Basic research in nuclar physics and waterials science research is done in the high-current target orea.

The low-current terget area (target 2) can accept up tc 0.1 uA of proton been or de used for measurements with neutrons from target 1 . The horizontal proton bean in target 2 strikes torgets mich can be vlewed at a variety of angles (from $7.5^{\circ}$ to $\left.165^{\circ}\right)$ to the proton bem. We have Implemented $30-m$ flight paths at $7.5^{\prime}, 15^{\circ}$. and $30^{\circ}$ to study $(p, x n)$. and $(p, x p)-t y p e$ reactions, and are consldering longer fitght patis and other angles. In turget 2. We have iso developed rive rapability to measure (for 800-MeV-proton spllution rextions): il spotial distributione of (atsolute) 'thermal' neutron surface fluxes from moderators. 2) obsolute neutron spectra for eneroles? 10 ? and 3) niutron pulse shapes for emergles $<0.172$ ev. He use this unfoue experfaental capabfilty (combined with excellent computational suprort) to optimize the neutronics of the inigh-current production target system in tems of neutron beam fluxes ano pulse withs, arid minimizing highenergy neutron beam contamination and assoctated backs. ounds $5,6,7$.

Using targets placed in the WNR besm channe?, we have constructed a $200-m$ flight path at $0^{\circ}$ to the proton beam. This flight patn combined wth unique wh: proton pulse structure* allows high resolution experiments to be performed at neutron energies up to $800 \mathrm{MeV}$.

\section{Operating Characterititics}

With or whout the PSR proton beam, the WNR can operate in two modes. These modes are as follows:

- wt thout PSR

$\left\{\begin{array}{l}\text { micropulse mode } \\ \text { microsecond mode }\end{array}\right.$

- with PSR

short bunch high frequency mode

long bunch high

A summary of the WNR nroton pulse characteristics is given in Table 1. At present, the widh of the WWR proton pulse can be varled from 200 ps to 8 us. The PSR wll provide additlonal pulse-wdth and repetition-rate combinations with higher instantaneous intensitios, and more average proton currents.

\section{Neutronic Characteristics}

The varlous desfons of target talget-moderator and target-moderator-reflector configurations for terget i (see Fig. 2) are strongly influenced by the need for neutrons with energles ranging from. few me! to 800 Mev having rulse whths as nerrow is practical. We use a bare taroet to produce neutrons $w$ th chergies $z 100 \mathrm{kev}$ ! on unieflected 'fast. mocierator for neutron: wth energles 1 ev $\leq E \leq 100$ kev". and a reflected system for neutrons wth energles $\leq 1 \mathrm{eV}$.

The higin-resolution bare target presently used in taraet 1 consists of. Th cylinder $12.5-\mathrm{cm}$ dian by 15-cm longl placed in a water cooled Al canister. We messured the meutron spectrum lat $90^{\circ}$ to the protc- heaml from such a target: tha results are shown in Fig. A and compared win calculated predictions. The bare-target dats mere mesured

The nininum proton pulse width at the WW was
nessured to be opproximately 200 ps FWMM. This corresponds co single LAMpF alcropulse. 